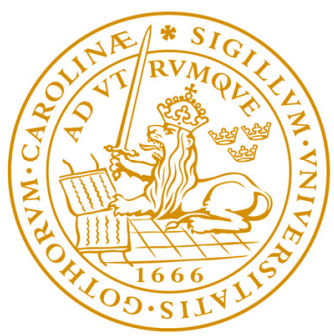

LUND UNIVERSITY

Faculty of Medicine

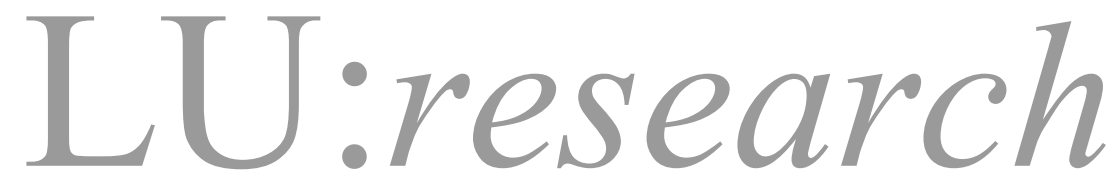

Institutional Repository of Lund University

This is an author produced version of a paper published in Cancer genetics and cytogenetics. This paper has been peer-reviewed but does not include the final publisher proof-corrections or journal pagination.

Citation for the published paper:

Rennstam, Karin and Jonsson, Goran and Tanner, Minna and Bendahl, Par-Ola and Staaf, Johan and Kapanen,

Anita and Karhu, Ritva and Baldetorp, Bo and Borg, Ake and Isola, Jorma.

"Cytogenetic characterization and gene expression profiling of the trastuzumab-resistant breast cancer cell line JIMT-1"

Cancer Genet Cytogenet, 2007, Vol: 172, Issue: 2, pp. 95-106.

http://dx.doi.org/10.1016/j.cancergencyto.2006.09.014

Access to the published version may

require journal subscription.

Published with permission from: Elsevier 


\section{Cytogenetic Characterization and Gene Expression Profiling of the Trstuzumab-Resistant Breast Cancer Cell Line JIMT-1}

Karin Rennstam $^{1 *}$, Göran Jönsson ${ }^{1}$, Minna Tanner ${ }^{2,3}$, Pär-Ola Bendahl ${ }^{1}$, Johan Staaf ${ }^{1}$, Anita I Kapanen $^{2}$, Ritva Karhu ${ }^{4}$, Bo Baldetorp ${ }^{1}, \AA_{\text {ke Borg }}{ }^{1}$ and Jorma Isola ${ }^{2}$

1) Department of Oncology, Clinical Sciences, Lund University, Lund, Sweden

${ }^{2)}$ Laboratory of Cancer Biology, Institute of Medical Technology, Tampere University and Tampere University Hospital, Tampere, Finland

3) Department of Oncology, Tampere University Hospital, Tampere, Finland

4) Laboratory of Cancer Genetics, Institute of Medical Technology, Tampere University and Tampere University Hospital, Tampere, Finland

* Correspondence to:

Karin Rennstam

Department of Oncology

Clinical Sciences

Lund University

SE-221 85 Lund

SWEDEN

Tel: +46-46 178515

Fax: +46-46 147327

E-mail: Karin.Rennstam@med.lu.se

Running title: Herceptin resistance in breast cancer

Key words: array-CGH, breast cancer, cell line, drug resistance, gene expression, HER-2 


\section{Footnote I:}

This study was supported by:

European Union Research Contract FP5 QLRT-1999-3126 to the Laboratory of Cancer Biology, Institute of Medical Technology, Tampere University and the Department of Molecular Biology, Max Planck Institute for Biophysical Chemistry, Göttingen. Further financial support was received from the Tampere University Hospital Research Foundation, Academy of Finland, Sigrid Juselius Foundation, Emil Aaltonen Foundation, the Finnish Cancer Foundation and the Max Planck Society.

The Swedish Cancer Foundation grant number 010631, Mrs. Berta Kamprad Foundation, Gunnar Nilsson Cancer Foundation, IngaBritt and Arne Lundberg Foundation, University Hospital of Lund Foundation, Franke and Margaretha Bergqvist Foundation, King Gustaf V Jubilee Foundation grant number 02:500. The microarray studies were performed in the SWEGENE ${ }^{\mathrm{I}}$ DNA microarray resource center, supported by grants from the Knut and Alice Wallenberg Foundation through the SWEGENE program.

Inquiries about the JIMT-1 cell line should be addressed to the German cell line collection $\mathrm{DSMZ}^{\mathrm{VI}}$.

Internet addresses:

${ }^{\mathrm{I}}$ http://swegene.onk.lu.se/

II http://base.thep.lu.se/

III http://genome.ucsc.edu/

IV http://www.ncbi.nih.gov/

${ }^{v}$ http://www.atcc.org/

VI http://www.dsmz.de 


\begin{abstract}
Resistance to the HER-2 targeting drug trastuzumab is observed clinically, but the lack of suitable experimental models hampers studies of resistance mechanisms. We characterized a HER-2 positive carcinoma cell line (JIMT-1) derived from a 62-year-old breast cancer patient, clinically resistant to trastuzumab. m-FISH revealed a complex hyperdiploid karyotype with numerous marker chromosomes and unbalanced translocations. CGH revealed numerous regions of copy number aberration (CNA). Further analysis by a-CGH identified 27 regions of CNA (16 amplified, 11 deleted). $38 \%$ of the genes in the amplified regions were overexpressed, compared to only $9 \%$ in regions of normal copy number ratios (CNR).

Accordingly, $26 \%$ of the genes in the deleted regions were underexpressed, compared to $10 \%$ in regions of normal CNR. Most amplified and overexpressed genes were located on chromosome 1 as well as on 8q, 12q14.1, 17q11-q21, and 20q13. In 17q11-q21 we identified two separate amplicons, the HER-2 amplicon, and a previously unreported amplicon at 17q21.31. Several aberrant genes are implicated in cancer development (e.g. JUN, CDK4 and $S L U G$ protooncogenes, and the drug/hormone metabolizing genes GSTM1 and CYP24). We conclude that cytogenetic and expression profiling of JIMT-1 revealed several new features that needs further characterization, which may shed light on the trastuzumab resistance.
\end{abstract}




\section{Introduction}

Breast cancer arises due to a series of recurrent alterations in the genome of the normal epithelial cell. The importance of these gene and chromosome alterations in the development and progression of solid tumors have been extensively characterized in the literature. For example, amplification of the HER-2 oncogene and overexpression of its concomitant protein is associated with an increased risk of relapse and death. According to some studies it is also associated with an altered response to hormonal and cytotoxic therapies [1]. The HER-2 oncogene is amplified and overexpressed in $\sim 20 \%$ of all human breast cancers [1]. The gene encodes a $185-\mathrm{kD}$ transmembrane tyrosine kinase receptor. The finding that monoclonal antibodies against this receptor can inhibit growth in cancer cells that overexpress the HER-2 receptor on the cell surface is considered a major discovery in breast cancer therapy [2]. This led to the development of a humanized monoclonal HER-2 antibody, trastuzumab, which has a profound growth-inhibitory effect in metastatic breast cancer [3, 4]. Trastuzumab (Herceptin $\left.{ }^{\circledR}\right)$ is currently used widely as treatment for metastatic breast cancer. It is effective alone, and especially in combination with taxanes or vinorelbine, in $60-80 \%$ of HER-2 positive tumors [5]. However, for the remaining patients Herceptin ${ }^{\circledR}$ has no beneficial effect, even though the HER-2 gene is amplified and the protein is overexpressed, in the

primary tumor as well as in the metastasis [6]. The development of primary resistance to trastuzumab must therefore be influenced by other, currently unknown factors. Identification of molecular markers of potential resistance mechanisms could be useful to distinguish potentially non-responding patients even before the start of Herceptin ${ }^{\circledR}$ treatment. New drugs that might be given alone or in combination with trastuzumab in order to circumvent the resistance, may potentially be developed based on the knowledge of such resistance mechanisms. 
At present, the lack of suitable experimental model systems, impede studies of trastuzumab resistance. Here we characterize a novel cell line derived from a breast cancer patient with a Herceptin ${ }^{\circledR}$ resistant tumor by multicolor fluorescent in situ hybridization (mFISH), comparative genomic hybridization (CGH), microarray based CGH (a-CGH), and gene expression pattern by c-DNA microarray. 


\section{Materials and Methods}

\section{The JIMT-1 cell line and xenograft}

The clinical history of the patient from which the cell line and xenografts were derived has been described elsewhere [7]. Briefly, a 62 year old woman, initially diagnosed with a grade III invasive ductal breast cancer (stage T2N1M0) underwent surgery with radical mastectomy and axillary lymph node evacuation. Metastases were found in 1 of 12 lymph nodes examined. The patient was recruited to a randomized adjuvant trastuzumab therapy trial, where she received a combination of trastuzumab $(4 \mathrm{mg} / \mathrm{kg}$ initiation dose, continued with $2 \mathrm{mg} / \mathrm{kg}$ ) and vinorelbine $\left(25 \mathrm{mg} / \mathrm{m}^{2}\right)$, followed by three courses of standard dose CEF (cyclophosphamide $600 \mathrm{mg} / \mathrm{m}^{2}$, epirubicin $60 \mathrm{mg} / \mathrm{m}^{2}, 5$-fluorouracil $600 \mathrm{mg} / \mathrm{m}^{2}$, three weekly i.v.) and post-operative radiation therapy (50Gy). Only two weeks after the completion of radio therapy the patient presented an ipsilateral pleural effusion containing carcinoma cells. The disease progressed although therapy for distant metastatic disease was initiated, and a palliative pleural puncture was clinically necessary. The material for cell culture was obtained from this second aspirate. The patient died twelve weeks after first diagnosis of distant metastasis. Approval to use cancer cells for culture and experimental studies was obtained from the patient and the local ethical committee prior to the study. The resulting cell line, designated JIMT-1, showed continuous growth, and can recover from cryopreservation (FBS 90\%/DMSO 10\%). In order to test xenograft tumor formation, approximately 3-5 million trypsinized JIMT-1 cells in PBS were injected subcutaneously into nude mice. 


\section{Genetic and phenotypic characterization}

The primary breast tumor from the patient and formalin-fixed paraffin-embedded JIMT-1 xenografts has been studied by immunohistochemistry (IHC) for estrogen receptor (ER), progesterone receptor (PgR), HER-2, Ki67, pan-cytokeratin, and TP53 previously [7]. Fluorescence and chromogenic in situ hybridization (FISH and CISH, respectively) were carried out to study the amplification of known breast cancer oncogenes. The hybridization protocols and the digoxigenin-labeled genomic BAC and PAC probes for $H E R-2, E G F R$, TOPOII $\alpha, c-M Y C, C C N D 1$, and 20q13 have been characterized in our previous studies $[6,8$, 9]. Denaturating high performance liquid chromatography (DHPLC) was carried out to detect mutations in the $p 53$ gene (exons 5-9) as described elsewhere [10]. DNA flow cytometry was carried out according to an established protocol [11].

\section{Cytogenetic analyses}

The JIMT-1 cells were harvested (trypsinized) after exposure to colcemid for 4 hours, followed by a hypotonic shock in $0.05 \mathrm{M} \mathrm{KCl}$, and fixation in methanol/acetic acid. m-FISH was carried out according to the manufacturer's instructions (X-Cyte kit, MetaSystems Gmbh, Altlusheim, Germany) [12]. CGH was performed as previously described [12-14]. DNA genotyping analysis to confirm the identity of JIMT-1 cells was based on the PowerPlex 1.2 genotyping kit (Promega, Madison, WI, USA).

\section{Preparation and printing of cDNA microarrays.}

Arrays containing 27,498 human cDNA probes were produced by the SWEGENE DNA microarray resource center, Department of Oncology, Lund University, Sweden ${ }^{\mathrm{I}}$. Out of these probes 17,517 represent unique UniGene clusters according to UniGene Build 160. Printed probes were prepared from human cDNA clones (Research Genetics, Huntsville, AL, USA) 
by vector-specific PCR amplification. All PCR products were verified by agarose gel electrophoresis and purified by size-exclusion filtration. After purification, PCR products were recovered in water, adjusted to $50 \% \mathrm{DMSO}$, and printed on amino-silane-coated glass slides (UltraGAPS; Corning, Acton, MA, USA) using a MicroGrid2 robot (BioRobotics, Cambridgeshire, UK) equipped with MicroSpot2500 pins (BioRobotics).

\section{Copy number and expression analysis on cDNA microarrays}

For CGH experiments on c-DNA arrays, $6 \mu \mathrm{g}$ of genomic DNA from the JIMT-1 cell line, xenograft, and normal control was labeled with Cy3-dUTP or Cy5-dUTP by random priming at $37^{\circ} \mathrm{C}$ overnight. Labeled DNAs were purified using the CyScribe GFX Purification Kit (Amersham Biosciences, Buckinghamshire, UK) according to the manufacturer's instructions. Test and reference DNAs were, along with Cot-1 DNA, yeast t-RNA, poly dA and poly dT, hybridized in $40 \mu \mathrm{l}$ of Universal Hybridization Solution (Corning) onto the arrays in a CMTHybridization Chamber (Corning) and submerged in a water bath at $42^{\circ} \mathrm{C}$ for $72 \mathrm{~h}$.

Pre-hybridization treatment of arrays and hybridization were performed according to instructions provided with the Universal Microarray Hybridization Kit (Corning). Arrays were then washed according to Pronto! ${ }^{\text {TM }}$ Microarray Reagent Systems (Corning). Each a-CGH experiment was verified using dye-swap hybridizations.

For the gene expression analysis, a standard reference RNA (Universal Human Reference RNA; Stratagene, La Jolla, CA, USA) was used. A second gene expression analysis was carried out using RNA from a pool of HER-2 amplified but trastuzumab-sensitive breast cancer cell lines (CAMA-1, MDA-361, SK-BR-3, EFM-192, UACC-893, UACC-812, MDA-453, ZR-75-30, and BT-474; grown under conditions recommended for each line). 
From each cell line and reference, $20 \mu \mathrm{g}$ of total RNA was indirectly labeled with Cy5-dUTP and Cy3-dUTP respectively, (Amersham Biosciences), and then hybridized overnight onto the array as otherwise described above.

\section{cDNA microarray data acquisition}

For a-CGH as well as for expression analysis, a confocal laser scanner (Agilent technologies, Palo Alto, CA, USA) was used to measure captured fluorescence intensities on the arrays after hybridization. Image analysis was performed with Gene Pix Pro 4.0 (Axon Instruments, Wheatherford, TX, USA), and the quantified data matrix was loaded into Bio Array Software Environment $\mathrm{BASE}^{\mathrm{II}}$ [15]. Background corrections of $\mathrm{Cy} 3$ and $\mathrm{Cy} 5$ intensities were calculated using the median feature and median local background intensities provided in the quantified data matrix. Within arrays, intensity ratios for individual probes were calculated as background corrected intensity of test sample divided by background corrected intensity of reference sample. Probes with a signal-to-noise ratio $(\mathrm{SNR})<2$ in either of the two channels, or with a spot diameter $<40 \mathrm{~nm}$ were excluded from further analysis and regarded as missing values. Arrays were normalized using a BASE implementation of the pin-based LOWESS algorithm $[16,17]$. The mean value from the two corresponding dye-swap experiments was used for further analysis. Mapping information regarding clone locations and cytogenetic banding were retrieved from the UCSC genome browser ${ }^{\mathrm{III}}$ (July 2003 freeze) and UniGene build 160 at $\mathrm{NCBI}^{\mathrm{IV}}$.

\section{Identification of regions of amplification or deletion}

Regions of amplifications and deletions in the a-CGH data were defined as a ratio $>2.0$ or $<0.5$, respectively, in at least three adjacent c-DNA clones. Amplified regions were then extended to include neighboring genes with a ratio $>1.5$ [18]. With technical flaws in 
consideration we also extended the regions, allowing one or two genes with a ratio below 1.5 if the next gene had a ratio $>1.5$, or not more than three genes below 1.5 if the next gene had a ratio $>2.0$. In the same way we extended deleted regions to include neighboring genes with a ratio $<0.67(1 / 1.5)$, allowing not more than two genes with a ratio above 0.67 if the next gene had a ratio $<0.67$, or not more than three genes above 0.67 if the next gene had a ratio $<0.5$.

\section{Establishment of statistical correlation between a-CGH and expression analysis}

We employed a leave-one-out method based on Spearman correlation, to produce a list of genes contributing the most to the correlation between a-CGH and expression ratios. For each of the genes we calculated the difference between the Spearman correlation coefficient with and without the gene, sorted the differences, and excluded the one contributing most to the positive correlation. The excluded gene was ranked as number one. By repeating this procedure for the remaining set of genes we found the second one on the list, etc. 


\section{Results}

JIMT-1 cells grow as an adherent monolayer to confluence in 7-10 days and have the appearance of medium-sized epitheloid cells with variable nuclear size. The cells can recover from cryopreservation and reach the original growth rate in 2 weeks. Injection of JIMT-1 cells subcutaneously into nu/nmri nude mice lead to formation of xenograft tumors in $\sim 90 \%$ of the animals tested. Histopathologically the xenograft tumors represent a high-grade adenocarcinoma. The PowerPlex genotype of JIMT-1 cells (Amelogenin: X; CS1P0: 12,13; D13S317: 8,13; D16S539: 11; D5S818: 12,13,14; D7S820: 12; TH01: 7, TPOX: 8; vWA: 18) matched with that obtained from the primary tumor tissue of the patient, and showed no resemblance with any of the cell lines reported in the ATCC cell line database ${ }^{\mathrm{V}}$.

\section{Genetic and phenotypic characterization}

In order to reveal the susceptibility to trastuzumab therapy, the primary tumor of the patient was screened for amplification of the HER-2 gene and overexpression of its concomitant protein by CISH and IHC, respectively. The tumor displayed a $3+$ overexpression by IHC, and was shown to be amplified by CISH. Gene amplification (approximately 20-30 copies/cell) was found by FISH in the pleural metastatic cells and in the JIMT-1 cells after 10 passages. Gene amplification of HER-2 was found also in the xenograft tumors by CISH [7].

IHC of the primary breast tumor and a JIMT-1 xenograft showed no staining for ER and PgR, but strong immunopositivity for p53. Abundant Ki-67 labeling evidenced a high cell proliferation rate. The epithelial origin of the JIMT-1 cells was confirmed by a strongly positive pan-cytokeratin immunostaining.

FISH analysis of genes commonly amplified in breast cancer (other than HER-2) revealed amplification of 20q13, whereas no amplification was found in EGFR, TOPOII $\alpha, c-$ 
$M Y C$, and CCND1. A point mutation was found in the p53 gene (exon 7) by DHPLC analysis. The results are summarized in Table 1.

\section{Cytogenetic characterization by m-FISH and CGH.}

Cytogenetic analysis with m-FISH revealed a complex hyperdiploid karyotype with numerous chromosome aberrations. On average, there were 52-57 chromosomes, which is in line with the DNA flow cytometry DNA-index of 1.35. Several complex translocations occurred, implicating chromosomes $1,8,12$, and 17 as being frequently involved in genetic recombination (Fig. 1; Table 2).

Chromosomal CGH of the JIMT-1 cell line and xenograft revealed copy number gains at 1p31-p32, 1q23-q25, 1q41-q42, 5p11-p13, 6p, 8q, 9q22-qter, 11p11-p15.2, 12q13q14, 17q12-q22, 18p11.21-pter, 20q, and losses at 1p11-p13, 4p11-p15.3, 4q33-qter, 5q14, 7q21-q32, 9p13-pter, 18q, and Xp (Table 3). The CGH findings matched well with those observed in the untreated primary tumor of the patient. The copy number imbalances were the same, except for the losses at 7q and Xp, which were not found in the primary tumor.

\section{Cytogenetic characterization by a-CGH}

The correlation between JIMT-1 cell line and xenograft a-CGH was very high (data not shown). a-CGH mapping identified 16 independent amplification sites, and 11 independent

sites of deletion, which are all listed in Table 3. Amplicons ranged in size from $0.52 \mathrm{Mb}$ up to $28.8 \mathrm{Mb}$, and deleted regions ranged from $1.92 \mathrm{Mb}$ up to $48.51 \mathrm{Mb}$. Several previously undescribed patterns of copy number aberrations (CNAs) were detected, including five individual amplicons and one deletion on chromosome 1, amplifications on 12q14.1 and $17 \mathrm{q} 21.31$, the latter being located at $3.5 \mathrm{Mb}$ distance from the $H E R-2$ region. 


\section{Comparison of chromosomal CGH and a-CGH}

The concordance between $\mathrm{CGH}$ and a-CGH was generally very high. As expected, several large amplifications found by chromosomal CGH was explained by, often more than one, narrow, but high-level amplification found by a-CGH. In particular the aberrations on chromosomes $1,8,11,12$, and 17 revealed more detailed aberration patterns by a-CGH (Fig. 2; Table 3).

\section{Correlation between a-CGH copy number aberrations and gene expression}

When comparing the gene expression analysis data to that of a-CGH, a clear correlation between CNAs and the level of gene expression was found. A large fraction (38\%) of the genes in the amplified regions were also overexpressed (i.e. belonged to the upper $10 \%$ of expression ratios), compared to only $9 \%$ in regions of normal copy number ratios $(\mathrm{p}<<0.001)$. Accordingly, 26\% of the deleted regions were also underexpressed (i.e. belonged to the lower $10 \%$ expression ratios), compared to $10 \%$ in regions of normal copy number ratios $(p<<0.001)$. Expression ratios for chromosomes 1, 8, 11, 12, and 20, correlating to CGH and a-CGH data, are shown in Fig. 2, and the expression ratio of chromosome 17 in correlation to $\mathrm{CGH}$ and a-CGH data is shown in Fig. 3. A second gene expression hybridization using RNA from a pool of HER-2 amplified, but trastuzumab sensitive, breast cancer cell lines revealed that the genes from the amplicon at 17q21.31 are overexpressed in JIMT-1 compared to trastuzumab sensitive breast cancer cell lines (Fig. 4).

The Spearman rank correlation between CNA by a-CGH and gene expression ratios was 0.26 ( $n=9898$ genes). The 50 genes contributing the most to the positive correlation are shown in figure 5. Of these, 16 are positioned on the highly aberrant chromosome 1 , five are located on chromosome 12, and 11 genes are located on chromosome 17 . Thirteen of the 50 genes are hypothetical proteins or transcribed sequences coding for proteins with unknown 
function. Of the remaining 37 genes 27 (73\%) are implicated in cell cycle control, transcription or apoptosis. Ten genes encode proteins with functions not directly linked to the development of cancer. 


\section{Discussion}

We report here the genetic characterization of a new HER-2 receptor positive cell line and xenograft tumors derived from a trastuzumab-resistant breast cancer patient. JIMT-1 cells and the xenograft tumors carry phenotypic hallmarks of an HER-2 positive breast cancer (i.e., histologically representing a high-grade invasive ductal carcinoma, lacking expression of ER and $\mathrm{PgR}$ ). Moreover, the primary tumor and the xenograft were characterized by a high tumor proliferation rate and a mutation of $\mathrm{p} 53$, which both are common features in HER-2 positive tumors [1]. FISH revealed amplification of 20q13, which is a well-characterized amplification in high grade breast tumors $[19,20]$. In order to get a detailed overview of the genetic aberrations of the cell line, several cytogenetic characterization methods were used.

Cytogenetic analysis with m-FISH revealed a complex hyperdiploid karyotype with numerous marker chromosomes and unbalanced translocations. The strength of m-FISH is to reveal structural chromosome aberrations in complex karyotypes better than conventional G-banding techniques. However, even with m-FISH the nature of translocations remains obscure. For example, with m-FISH it is not possible to identify homogeneously staining regions (hsrs) of numerous amplicons that are known to translocate to various derivate chromosomes (often together). A complex m-FISH karyotype like the one found in JIMT-1 has been the main finding for all breast cancer cell lines known to carry HER-2 amplification (BT-474, MDA-361, SKBR-3, UACC-812, and UACC-893) [14]. Thus, other cytogenetic methods were needed to further characterize the genetic background of the Herceptin ${ }^{\circledR}$ resistance.

When studying JIMT-1 by chromosomal CGH, an aberration pattern typical for that of an aggressive breast cancer was found [21-23]. A high number of CNAs is by itself a predictor of poor clinical outcome, and in particular the gains on $8 \mathrm{q}, 17 \mathrm{q}$, and $20 \mathrm{q}$ have been 
shown to be connected to poor patient prognosis [13]. The CGH profiles of the primary tumor, JIMT-1 cell line, and its xenograft were identical in 17 of 19 CNAs found. The exceptions were the losses at $7 \mathrm{q}$ and $\mathrm{Xp}$, which were not found in the primary tumor. This may reflect clonal selection during metastatic process in the patient or during cell culture. Equally likely is that it is caused by the diluting effect of normal cell contamination in the paraffin block used for DNA extraction of the primary breast tumor of the patient. In general, the high resemblance of the CGH findings between the primary tumor and a cell line derived from its metastasis indicates the stability of the genotype.

The resolution of chromosomal CGH is limited, and is insufficient for in depth analysis of aberrant chromosomal regions. Microarray-based CGH provides a much higher resolution, allowing detection of rearrangements at the gene level. The concordance between $\mathrm{CGH}$ and a-CGH was generally high in the presented study. Several of the larger regions of amplification as detected by chromosomal CGH were found by a-CGH to contain often more than one, small amplicon with high-level amplification. Complex aberration patterns were seen on chromosome 1, and on segments $12 \mathrm{q} 14.1$ and 17q11.2-q21.

By using a-CGH in combination with m-RNA expression profiling it is possible to identify and characterize genes whose m-RNA expression is most significantly associated with amplification of the corresponding genomic template. We found a statistically significant correlation between CNA by a-CGH and expression level in amplified as well as deleted regions. This is clearly an indication that gene copy number is linked to expression level also in the case of lost genetic material, and that transcription from the remaining gene copy is not sufficient to compensate for the loss of the other allele.

A large number of the genes in these regions was also differentially expressed and have the potential to promote breast cancer progression. For example, the protooncogene $J U N$, located on 1p31-p32, is believed to encode the enhancer protein AP-1 that interacts 
directly with specific target DNA sequences to regulate gene expression, as well as the general transcription factor II B (TFIIB), located on 1p21-p22, that encodes a factor required for transcription initiation by RNA polymerase II. To our knowledge this gene has not previously been shown to undergo amplification in human cancers.

In the deleted region on chromosome subband 1p13.3, we found the GSTM1 (glutathione S-transferase M1) also to have a low level of expression. This enzyme detoxifies electrophilic compounds, including carcinogens, by conjugation with glutathione. Null mutations of this gene have been linked with an increase in a number of cancers, breast cancer being one [24], likely due to an increased susceptibility to environmental toxins and carcinogens.

The small amplicon on 12q14.1 harbors the Cyclin-dependent kinase 4 gene (CDK4), which is amplified and overexpressed. CDK4 is involved in cell-cycle control where it drives cells from G1 into s-phase. CDK4 has previously been shown linked to highly proliferating sporadic breast cancer [25]. Located $10.8 \mathrm{Mb}$ distal to this amplicon is the MDM2 gene, often thought to be the target gene in this region. MDM2 was neither amplified nor overexpressed in JIMT-1.

The Tumor suppressor gene SOCS2 (Suppressor of cytokine signaling 2), located on $12 \mathrm{q} 22$, is deleted and down regulated. Cytokines regulate the growth and differentiation of cells by binding to cell-surface receptors and activating intracellular signal transduction cascades such as the JAK-STAT pathway. The SOCS family of proteins negatively regulates cytokine signaling with respect to both magnitude and duration.

In the amplified region in chromosome segment 17q11.2-q21.1 the two transcriptional enhancers Thyroid hormone receptor-associated protein (TRAP-100) and PPAR-binding protein $(P P A R B P)$ are up regulated along with the HER-2 oncogene. This amplicon has previously been shown to contain approximately ten genes [26, 27]. To the best 
of our knowledge, the separate amplicon at $17 \mathrm{q} 21.31$ has not been previously described in breast cancer. This region contains genes that might be implicated in transcription and cell proliferation. The ETS variant gene 4 (ETV4) binds to the E1A enhancer, which in turn can activate the promoters of various matrix metalloproteinases, genes whose expression is associated with tumor cell invasion and metastasis. Palmitoylated membrane protein 2 and 3 (MAGUK2 and $M A G U K 3$ ) interact with the cytoskeleton and regulate cell proliferation. These genes are also overexpressed when comparing JIMT-1 to other HER-2 overexpressing, but trastuzumab sensitive, breast cancer cell lines indicating that this region may harbor genes of importance for trastuzumab resistance.

Genes in other amplified regions may also play an important role for the malignancy of this particular cancer. The BBP-like protein $1(B L P 1)$ in chromosome subband 8p11.22, which is a protein that may have regulatory roles in cell death or proliferation signal cascades, and the Snail homolog $2(S L U G)$, located on 8q11, which encodes a member of the Snail family of $\mathrm{C} 2 \mathrm{H} 2$-type zinc finger transcription factors. The protein acts as a transcriptional repressor that binds to E-box motifs and also represses E-cadherin transcription in breast carcinoma. This protein is involved in epithelial-mesenchymal transitions and has antiapoptotic activity [28].

On chromosome arm $20 \mathrm{q}$ we found two protease inhibitors, possibly a part of the defense of the cancer cells against the immune response, which were amplified and overexpressed. The secretory leukocyte protease inhibitor (antileukoproteinase, SLPI) encodes a secreted inhibitor, which protects epithelial tissues from serine proteases. Its inhibitory effect protects epithelial surfaces from attack by endogenous proteolytic enzymes. Also the WAP four-disulfide core domain 2 (WFDC2) functions as a protease inhibitor. This gene is normally expressed in pulmonary epithelial cells, but has also been found to be expressed in some ovarian cancers. Also up regulated is the CYP24A1 gene, located on 20q13, 
which is a vitamin D 24-hydroxylase whose overexpression is likely to restrain growth control mediated by vitamin D. CYP24A1 has previously been recognized as a target gene in the 20q13 amplicon [29].

In conclusion, we have here characterized a new and intrinsically Herceptin ${ }^{\circledR}$ resistant cell line, JIMT-1. This cell line displays cytogenetic aberration patterns that are characteristic for aggressive breast carcinomas. $\mathrm{CGH}$ and a-CGH revealed numerous CNAs, some previously described in the literature, and some are to our knowledge novel findings. A large number of the genes in the aberrant regions were also differentially expressed, and have the potential to promote breast cancer progression. Studies of resistance to trastuzumab have up until now been hindered by the lack of suitable model systems. The JIMT-1 cell line is to our knowledge the first experimental model for studies of primary trastuzumab resistance. 


\section{References}

1. Ross JS, Fletcher JA. HER-2/neu (c-erb-B2) gene and protein in breast cancer. Am J Clin Pathol 1999;112:S53-67.

2. Hudziak RM, Lewis GD, Winget M, Fendly BM, Shepard HM, Ullrich A. p185HER2 monoclonal antibody has antiproliferative effects in vitro and sensitizes human breast tumor cells to tumor necrosis factor. Mol Cell Biol 1989;9:1165-1172.

3. Baselga J, Albanell J, Molina MA, Arribas J. Mechanism of action of trastuzumab and scientific update. Semin Oncol 2001;28:4-11.

4. Slamon DJ, Leyland-Jones B, Shak S, Fuchs H, Paton V, Bajamonde A, Fleming T, Eiermann W, Wolter J, Pegram M, Baselga J, Norton L. Use of chemotherapy plus a monoclonal antibody against HER2 for metastatic breast cancer that overexpresses HER2. N Engl J Med 2001;344:783-792.

5. Cardoso F, Piccart MJ, Durbecq V, Di Leo A. Resistance to trastuzumab: a necessary evil or a temporary challenge? Clin Breast Cancer 2002;3:247-257; discussion 258249.

6. Tanner M, Jarvinen P, Isola J. Amplification of HER-2/neu and topoisomerase II alpha in primary and metastatic breast cancer. Cancer Res 2001;61:5345-5348.

7. Tanner M, Kapanen AI, Junttila T, Raheem O, Grenman S, Elo J, Elenius K, Isola J. Characterization of a novel cell line established from a patient with Herceptin-resistant breast cancer. Mol Cancer Ther 2004;3:1585-1592.

8. Tanner MM, Karhu RA, Nupponen NN, Borg A, Baldetorp B, Pejovic T, Ferno M, Killander D, Isola JJ. Genetic aberrations in hypodiploid breast cancer: frequent loss of chromosome 4 and amplification of cyclin D1 oncogene. Am J Pathol 1998;153:191-199.

9. Tanner MM, Tirkkonen M, Kallioniemi A, Isola J, Kuukasjarvi T, Collins C, Kowbel D, Guan XY, Trent J, Gray JW, Meltzer P, Kallioniemi OP. Independent amplification and frequent co-amplification of three nonsyntenic regions on the long arm of chromosome 20 in human breast cancer. Cancer Res 1996;56:3441-3445.

10. Keller G, Hartmann A, Mueller J, Hofler H. Denaturing high pressure liquid chromatography (DHPLC) for the analysis of somatic p53 mutations. Lab Invest 2001;81:1735-1737.

11. Baldetorp B, Ferno M, Bendahl PO, Fallenius G, Idvall I, Akerman M, Killander D. Proliferative index obtained by DNA image cytometry. Does it add prognostic information in Auer IV breast cancer? Anal Quant Cytol Histol 1998;20:144-152.

12. Karhu R, Ahlstedt-Soini M, Bittner M, Meltzer P, Trent JM, Isola JJ. Chromosome arm-specific multicolor FISH. Genes Chromosomes Cancer 2001;30:105-109.

13. Rennstam K, Ahlstedt-Soini M, Baldetorp B, Bendahl PO, Borg A, Karhu R, Tanner M, Tirkkonen M, Isola J. Patterns of chromosomal imbalances defines subgroups of breast cancer with distinct clinical features and prognosis. A study of 305 tumors by comparative genomic hybridization. Cancer Res 2003;63:8861-8868.

14. Kytola S RJ, Nordgren A, Karhu R, Farnebo F, Isola J, Larsson C. Chromosomal alterations in 15 breast cancer cell lines by comparative genomic hybridization and spectral karyotyping. Genes Chromosomes Cancer 2000;28:308-317.

15. Saal LH, Troein C, Vallon-Christersson J, Gruvberger S, Borg A, Peterson C. BioArray Software Environment (BASE): a platform for comprehensive management and analysis of microarray data. Genome Biol 2002;3:SOFTWARE0003.

16. Yang YH, Dudoit S, Luu P, Lin DM, Peng V, Ngai J, Speed TP. Normalization for cDNA microarray data: a robust composite method addressing single and multiple slide systematic variation. Nucleic Acids Res 2002;30:e15. 
17. Cleveland WS DS. Locally weighted regression: an approach to regression analysis by local fitting. J Am Stat Assoc 1988;83:596-610.

18. Hyman E, Kauraniemi P, Hautaniemi S, Wolf M, Mousses S, Rozenblum E, Ringner M, Sauter G, Monni O, Elkahloun A, Kallioniemi OP, Kallioniemi A. Impact of DNA amplification on gene expression patterns in breast cancer. Cancer Res 2002;62:62406245.

19. Collins C, Rommens JM, Kowbel D, Godfrey T, Tanner M, Hwang SI, Polikoff D, Nonet G, Cochran J, Myambo K, Jay KE, Froula J, Cloutier T, Kuo WL, Yaswen P, Dairkee S, Giovanola J, Hutchinson GB, Isola J, Kallioniemi OP, Palazzolo M, Martin C, Ericsson C, Pinkel D, Gray JW, et al. Positional cloning of ZNF217 and NABC1: genes amplified at 20q13.2 and overexpressed in breast carcinoma. Proc Natl Acad Sci U S A 1998;95:8703-8708.

20. Tanner MM, Tirkkonen M, Kallioniemi A, Holli K, Collins C, Kowbel D, Gray JW, Kallioniemi OP, Isola J. Amplification of chromosomal region 20q13 in invasive breast cancer: prognostic implications. Clin Cancer Res 1995;1:1455-1461.

21. Seute A, Sinn HP, Schlenk RF, Emig R, Wallwiener D, Grischke EM, Hohaus S, Dohner H, Haas R, Bentz M. Clinical relevance of genomic aberrations in homogeneously treated high-risk stage II/III breast cancer patients. Int J Cancer 2001;93:80-84.

22. Tirkkonen M, Tanner M, Karhu R, Kallioniemi A, Isola J, Kallioniemi OP. Molecular cytogenetics of primary breast cancer by CGH. Genes Chromosomes Cancer 1998;21:177-184.

23. Isola JJ, Kallioniemi OP, Chu LW, Fuqua SA, Hilsenbeck SG, Osborne CK, Waldman FM. Genetic aberrations detected by comparative genomic hybridization predict outcome in node-negative breast cancer. Am J Pathol 1995;147:905-911.

24. Zheng T, Holford TR, Zahm SH, Owens PH, Boyle P, Zhang Y, Wise JP, Sr., Stephenson LP, Ali-Osman F. Cigarette smoking, glutathione-s-transferase M1 and t1 genetic polymorphisms, and breast cancer risk (United States). Cancer Causes Control 2002;13:637-645.

25. An HX, Beckmann MW, Reifenberger G, Bender HG, Niederacher D. Gene amplification and overexpression of CDK4 in sporadic breast carcinomas is associated with high tumor cell proliferation. Am J Pathol 1999;154:113-118.

26. Kauraniemi P, Barlund M, Monni O, Kallioniemi A. New amplified and highly expressed genes discovered in the ERBB2 amplicon in breast cancer by cDNA microarrays. Cancer Res 2001;61:8235-8240.

27. Kauraniemi P, Kuukasjarvi T, Sauter G, Kallioniemi A. Amplification of a 280kilobase core region at the ERBB2 locus leads to activation of two hypothetical proteins in breast cancer. Am J Pathol 2003;163:1979-1984.

28. Fujita N, Jaye DL, Kajita M, Geigerman C, Moreno CS, Wade PA. MTA3, a Mi2/NuRD complex subunit, regulates an invasive growth pathway in breast cancer. Cell 2003;113:207-219.

29. Albertson DG, Ylstra B, Segraves R, Collins C, Dairkee SH, Kowbel D, Kuo WL, Gray JW, Pinkel D. Quantitative mapping of amplicon structure by array CGH identifies CYP24 as a candidate oncogene. Nat Genet 2000;25:144-146. 


\section{Legends for Figures}

Figure 1: m-FISH karyotype of a typical JIMT-1 metaphase spread. Several aberrations in chromosome number, and numerous structural chromosome aberrations, are detectable.

Figure 2: Chromosomal CGH, a-CGH, and expression ratios for chromosomes 1, 8, 11, 12 and 20. Regions of amplification and deletions, as seen by CGH (solid black line), are defined in more detail by a-CGH (blue dots). Aberrant a-CGH ratios are often corresponding to differential expression ratios (black dots). For chromosome 1, the segment 1p12-p13.3 is presented also in $\log 2$ scale (inserts), to graphically illustrate the deletion and underexpression of the corresponding genes.

Figure 3: Detailed analysis of chromosome 17. The broad amplification peak detected with conventional CGH (solid black line) is explained by two very narrow amplicons by a-CGH (blue dots). The proximal amplicon, located on 17q11.2-q21.1, harbors the HER-2 oncogene. The distal amplicon, located on 17q21.31, contains no known oncogenes. FISH-analysis, using a probe constructed from the BAC clone CTD2533L8, which has been mapped to 17q21.31, reveals a 10-fold amplification (insert; red signals=BAC probe). The top chart shows that the two amplified regions are also abundantly overexpressed. The CGH microscopy image of chromosome 17 , displayed at the base of the figure, shows that the amplification is high enough to be visualized by eye.

Figure 4: Gene expression ratio profiles for JIMT-1 using A) standard reference RNA (Universal Human Reference RNA; Stratagene), and B) RNA from a pool of $H E R-2$ amplified and trastuzumab-sensitive cell lines. The amplicon containing HER-2 (between blue lines) is no longer overexpressed when comparing JIMT-1 to other HER-2 overexpressing 
cells, as expected. The region on 17q21.31 (between red lines), however, shows a much higher expression in JIMT-1 than in the trastuzumab-sensitive breast cancer cell lines, indicating that this region may harbor genes of importance for trastuzumab resistance.

Figure 5: List of the 50 genes contributing most to the positive Spearman correlation between CNA and a-CGH and gene expression ratios. The genes have been listed according to their position in the genome. The order according to impact on the Spearman correlation is shown to the left (1=highest impact; $2=$ second highest and so on). The color maps to the right illustrate the copy number and expression ratios (CNR and ExpR, respectively) for each gene. CNR for the xenograft has been added for comparison. 
Table 1. Genotypic and phenotypic characterization of the trastuzumab resistant breast cancer cell line JIMT-1.

$\begin{array}{lcc}\text { Gene } & \text { Amplification status by FISH } & \text { Amplification status by a-CGH } \\ \text { HER-2 } & \text { Yes* } & \text { Yes } \\ \text { EGFR } & \text { No } & \text { No } \\ \text { TOPOII } & \text { No } & \text { No } \\ c-M Y C & \text { No } & \text { No } \\ \text { CCND1 } & \text { No } & - \\ 20 \mathrm{q} 12-\mathrm{q} 13 & \text { Yes } & \text { Yes }\end{array}$

Protein immunohistochemistry

HER-2 (mab CB-11)

overexpression $(3+)$

ER

negative

$\mathrm{PgR}$

negative

p53

overexpression

Ki67

high expression

Pan-cytokeratin strongly positive

*(20-30 copies/cell; 17 centromere $=2$ copies $/$ cell $)$ 
Table 2: A typical JIMT-1 metaphase by m-FISH, revealing a hyperdiploid karyotype with many complex aberrations.

\section{Karyotype by m-FISH}

52-57,XX,der(1;3), der(1;4)t(X;1;4),+der(1;8)t(8;1;15),+der(1;19)t(19;1;12), der(2;3), $\operatorname{der}(2 ; 3) \mathrm{t}(12 ; 3 ; 2 ; 17 ; 18),+\operatorname{der}(2 ; 16),+\operatorname{der}(2 ; 22), \operatorname{del}(3),+\operatorname{der}(3 ; 7) \mathrm{t}(18 ; 7 ; 3), \operatorname{der}(3) \mathrm{t}(3 ; 16)$, $\operatorname{der}(3 ; 20), \operatorname{del}(4), \operatorname{der}(5) \mathrm{t}(5 ; 7), \operatorname{der}(5 ; 7), \operatorname{der}(6) \mathrm{t}(1 ; 6), \operatorname{der}(6 ; 16), \operatorname{der}(7) \mathrm{t}(7 ; 1 ; 7), \operatorname{der}(8 ; 15)$, $+\operatorname{der}(8 ; 17),+\operatorname{der}(8 ; 17) \mathrm{t}(8 ; 17 ; 8),+\operatorname{der}(8 ; 14),+\operatorname{der}(8 ; 15) \mathrm{t}(15 ; 8 ; 14),+\operatorname{der}(9 ; 12) x 1-2$, $\operatorname{der}(10) \mathrm{t}(3 ; 10),+\operatorname{der}(11) \mathrm{t}(1 ; 11), \operatorname{der}(13 ; 20), \operatorname{der}(13 ; 14), \operatorname{der}(13 ; 17) \mathrm{t}(16 ; 12 ; 17 ; 13)$, $\operatorname{der}(15 ; 20), \operatorname{der}(16 ; 21), \operatorname{der}(17 ; 22), \operatorname{del}(18), \operatorname{der}(18) \mathrm{t}(4 ; 18), \operatorname{del}(19), \operatorname{der}(20 ; 21)[\operatorname{cp} 13]$ 
Table 3: Cytogenetic aberrations of JIMT-1 as determined by CGH and a-CGH.

\begin{tabular}{|c|c|c|c|c|c|c|c|}
\hline \multirow[t]{2}{*}{$\begin{array}{c}\text { Amplification } \\
\text { by CGH }\end{array}$} & \multicolumn{3}{|c|}{$\begin{array}{c}\text { Amplification by } \\
\text { a-CGH }\end{array}$} & \multirow{2}{*}{$\begin{array}{c}\text { Deletion by } \\
\text { CGH }\end{array}$} & \multicolumn{3}{|c|}{$\begin{array}{c}\text { Deletion by } \\
\text { a-CGH }\end{array}$} \\
\hline & Location & Size $(\mathrm{Mb})$ & Ratio* & & Location & Size $(\mathrm{Mb})$ & Ratio* \\
\hline \multirow{4}{*}{ 1p31-p32 } & $1 \mathrm{p} 22.2$ & 1.25 & 3.04 & 1p11-p13 & 1p12-p13.3 & 32.67 & 0.43 \\
\hline & 1p31.3-p32.2 & 6.00 & 4.57 & $4 p 11-15.3$ & $4 p 12-p 15.32$ & 33.88 & 0.51 \\
\hline & 1p32.2-p32.3 & 2.23 & 3.46 & 4q33-qter & 4q34.1-qter & 16.29 & 0.46 \\
\hline & $1 \mathrm{p} 34.1-\mathrm{p} 34.2$ & 4.92 & 1.74 & $5 q 14$ & $5 q 13.3-q 15$ & 21.16 & 0.48 \\
\hline $1 q 23-q 25$ & $1 \mathrm{q} 23.2-\mathrm{q} 25.1$ & 17.34 & 2.18 & & 7q11.23-q21.11 & 13.87 & 0.55 \\
\hline $1 q 41-q 42$ & $1 q 42.12-q 42.13$ & 3.97 & 1.87 & $7 q 21-q 32$ & $7 \mathrm{q} 21.2-\mathrm{q} 22.1$ & 8.35 & 0.56 \\
\hline- & $3 q 22.3$ & 0.52 & 2.30 & 9p13-pter & - & & \\
\hline $5 p 11-p 13$ & - & & & - & $11 \mathrm{p} 15.1$ & 1.92 & 0.43 \\
\hline $6 p$ & - & & & & $11 \mathrm{p} 15.3-\mathrm{p} 15.5$ & 10.89 & 0.45 \\
\hline \multirow[t]{2}{*}{$8 \mathrm{q} 11.1-\mathrm{q} 23$} & 8p11.21-p12 & 3.24 & 2.08 & - & $12 \mathrm{q} 21.1-\mathrm{q} 21.2$ & 8.78 & 0.54 \\
\hline & 8q11.1-q13.1 & 21.36 & 1.88 & $18 \mathrm{q}$ & $18 \mathrm{q} 12.1-\mathrm{q} 22.3$ & 48.51 & 0.49 \\
\hline \multirow[t]{2}{*}{$9 q 22-q t e r$} & - & & & $\mathrm{Xp}$ & $\mathrm{Xp}$ & 44.79 & 0.53 \\
\hline & $11 \mathrm{p} 11.2-\mathrm{p} 13$ & 9.59 & 1.78 & & & & \\
\hline \multirow[t]{2}{*}{$11 \mathrm{p} 11-\mathrm{p} 15.2$} & $11 \mathrm{p} 14.2-\mathrm{p} 15.1$ & 8.70 & 2.00 & & & & \\
\hline & $11 \mathrm{p} 15.2-\mathrm{p} 15.3$ & 3.60 & 2.14 & & & & \\
\hline $12 q 13-q 14$ & $12 \mathrm{q} 14.1$ & 2.17 & 5.91 & & & & \\
\hline \multirow[t]{2}{*}{$17 q 12-q 22$} & $17 q 11.2-q 21.1$ & 9.20 & 6.92 & & & & \\
\hline & $17 q 21.31$ & 0.58 & 6.85 & & & & \\
\hline 18p11.21-pter & - & & & & & & \\
\hline $20 q$ & $20 q$ & 28.80 & 1.96 & & & & \\
\hline
\end{tabular}

*Median ratio of genes within amplified/deleted region. 


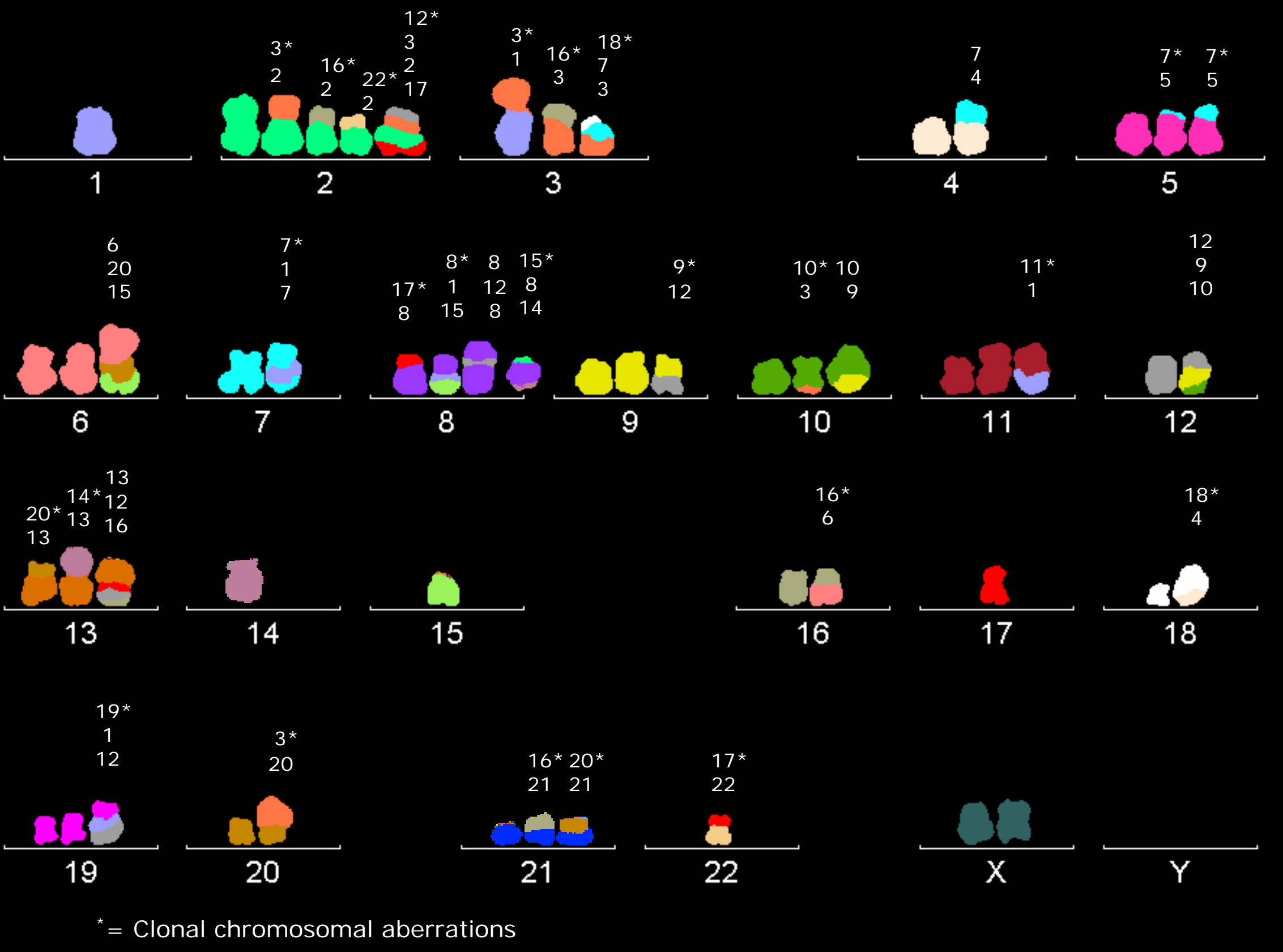

\section{Fiqure 1}



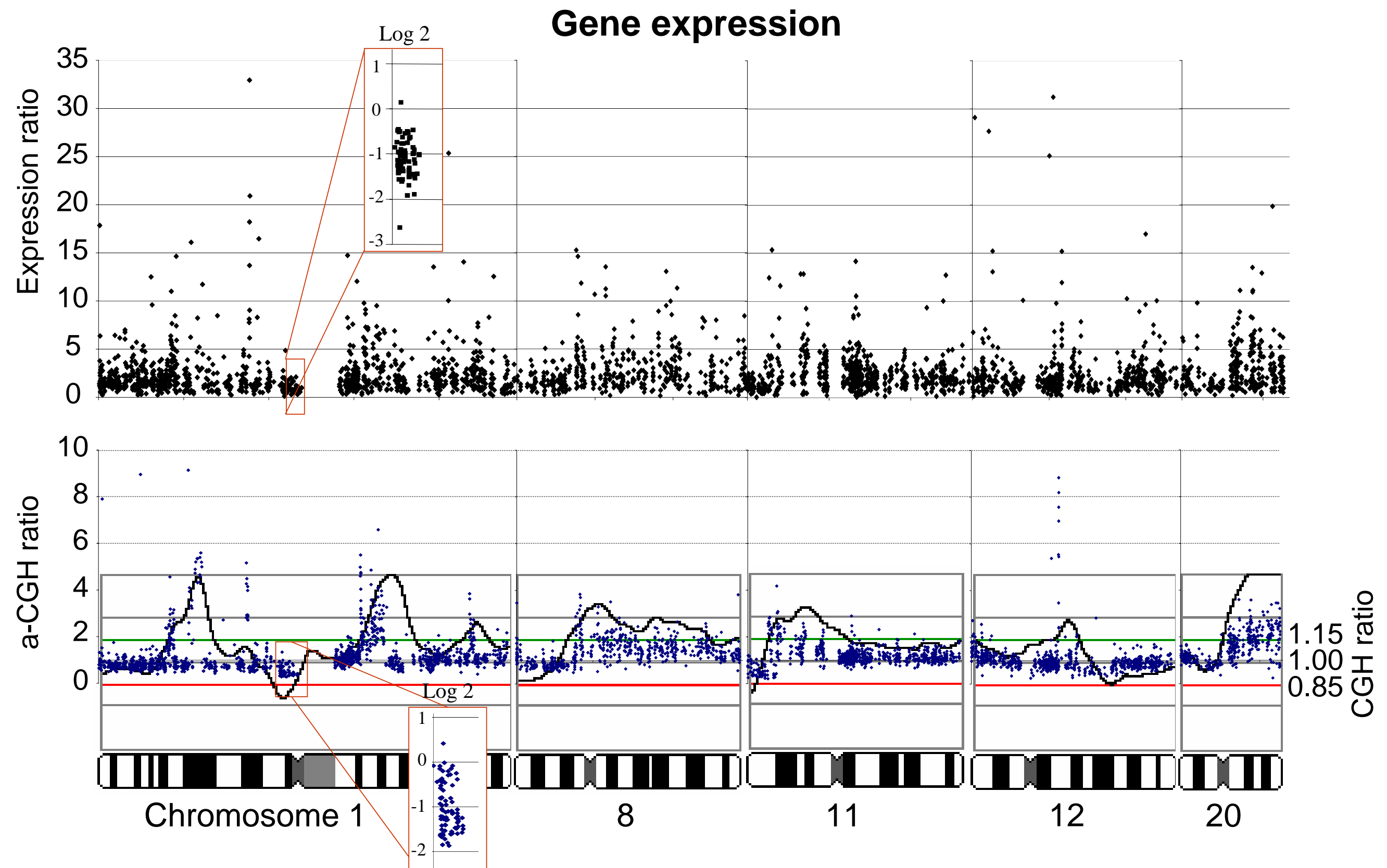

Figure 2

CGH and a-CGH 


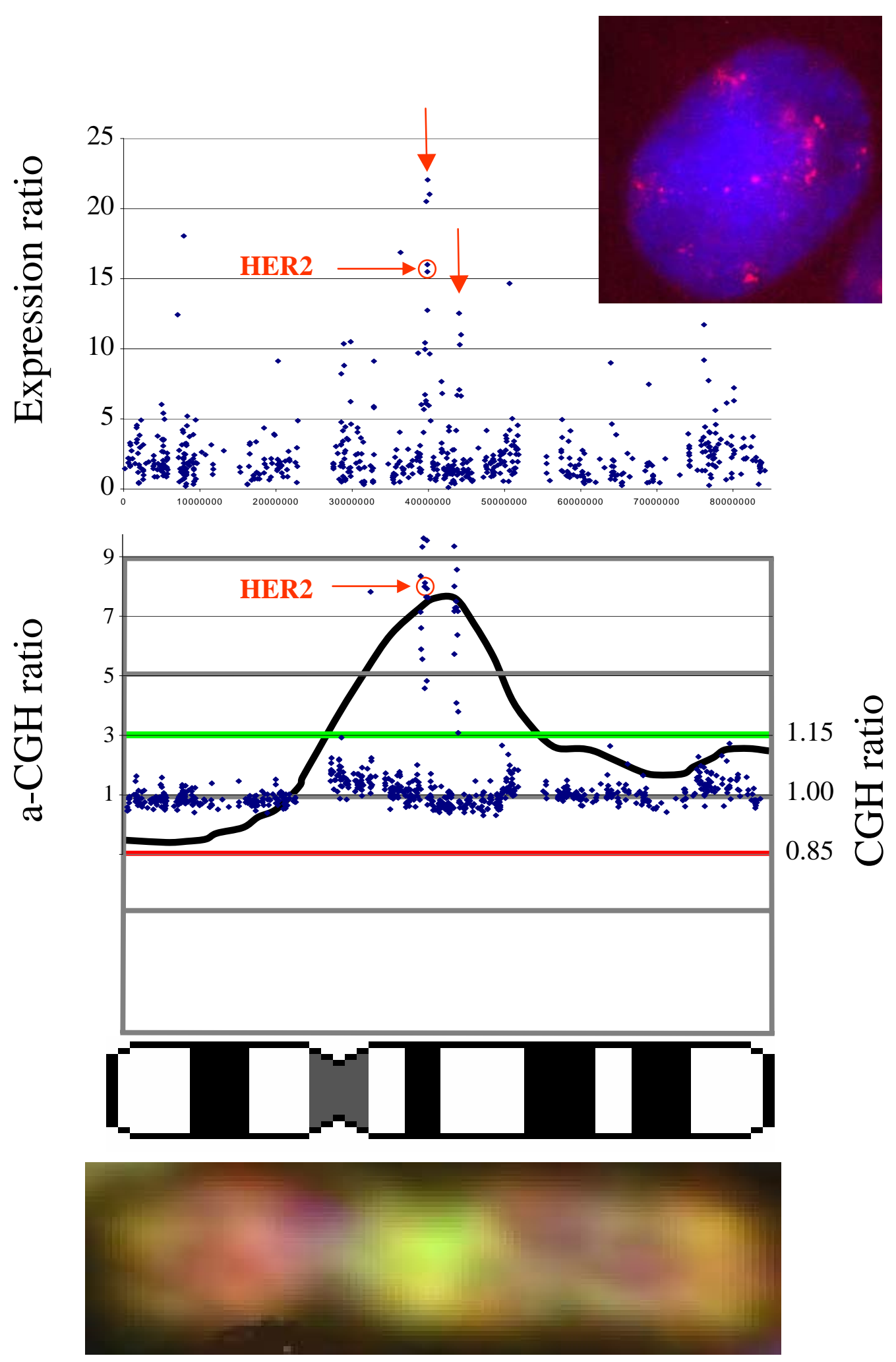

Figure 3 

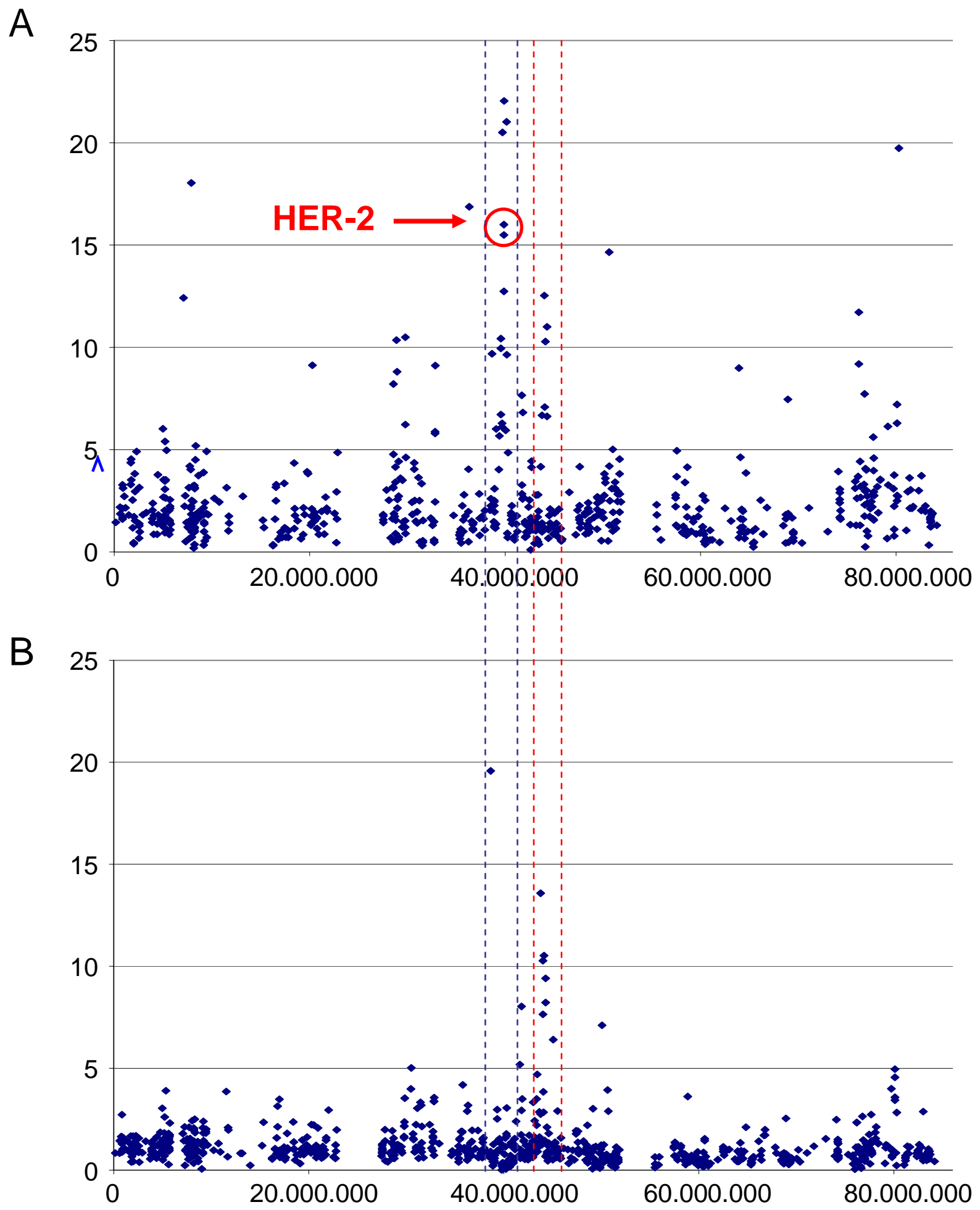

Figure 4 


\section{Order}

29 v-jun sarcoma virus 17 oncogene homolog (avian)

16 beta-amyloid binding protein precursor

38 general transcription factor IIB

11 Homo sapiens transcribed sequences

6 guanylate binding protein 1, interferon-inducible, $67 \mathrm{kDa}$

6 guanylate binding protein 2, interferon-inducible

2 guanylate binding protein 5

2 GSTM1: glutathione S-transferase M1

32 Homo sapiens mRNA; cDNA DKFZp586K1123 (from clone DKFZp586K1123)

mannosidase, alpha, class $1 \mathrm{~A}$, member 2

4 prefoldin 2

7 UDP-Gal:betaGlcNAc beta 1,4- galactosyltransferase, polypeptide 3

47 hypothetical protein FLJ12770

2 hypothetical protein FLJ21047

39 hypothetical protein FLJ14525

5 signal transducer and activator of transcription 1, 91kDa

5 eukaryotic translation initiation factor 4 gamma, 1

KIAA1102 protein

8 homer homolog 1 (Drosophila)

41 hypothetical protein LOC154807

paternally expressed 10

hypothetical protein FLJ14299

BBP-like protein 1

snail homolog 2 (Drosophila)

v-yes-1 Yamaguchi sarcoma viral related oncogene homolog

KIAA1750 protein

3 solute carrier family 39 (zinc transporter), member 4

9 SRY-BOX 6; SOX6

cyclin-dependent kinase 4

43 hepatocellularcarcinoma-associated antigen HCA557a

10 highly similarity to mitochondrial translation elongation factor

Homo sapiens, clone IMAGE:5268696, mRNA

suppressor of cytokine signaling 2

Zinc finger protein 198

stromal cell-derived factor 2

PPAR binding protein

Homo sapiens transcribed sequences

v-erb-b2 erythroblastic leukemia viral oncogene homolog 2, HER-2

proteasome (prosome, macropain) 26S subunit, non-ATPase, 3

thyroid hormone receptor-associated protein (100 kDa)

ets variant gene 4 (E1A enhancer binding protein, E1AF)

dual specificity phosphatase 3 (vaccinia virus phosphatase VH1-related)

membrane protein, palmitoylated 3 (MAGUK p55 subfamily member 3)

15 membrane protein, palmitoylated 2 (MAGUK p55 subfamily member 2)

hypothetical protein FLJ30656

secretory leukocyte protease inhibitor (antileukoproteinase)

WAP four-disulfide core domain 2

cytochrome P450, family 24, subfamily A, polypeptide 1

31 transmembrane, prostate androgen induced RNA

\section{Cell line}

\section{Locus}

$1 \mathrm{p} 32.3$

$1 \mathrm{p} 32.1$

$1 \mathrm{p} 31.3$

$1 \mathrm{p} 22.2$

$1 \mathrm{p} 22.2$

$1 \mathrm{p} 22.2$

$1 \mathrm{p} 22.2$

$1 \mathrm{p} 22.2$

$1 \mathrm{p} 13.3$

$1 \mathrm{p} 13$

$1 \mathrm{p} 12$

$1 \mathrm{q} 23.3$

$1 \mathrm{q} 23.3$

$1 \mathrm{q} 23.3$

$1 \mathrm{q} 24.2$

$1 \mathrm{q} 42.2$

2q32.2

3q27.1

$4 \mathrm{p} 13$

5q14.1

7q11.21

7q21.3

8p12

8p11.23

$8 q 11.21$

8q12.1

8q22.1

8q24.3

11p15.2

12q14.1

12q14.1

12q14.1

12q14.1

12q22

$13 q 12.11$

17q11.2

$17 \mathrm{q} 12$

$17 \mathrm{q} 12$

17q12

17q21.1

17q21.1

17q21.31

17q21.31

17q21.31

17q21.31

17q21.31

20q13.12

20q13.12

20q13.2

20q13.32

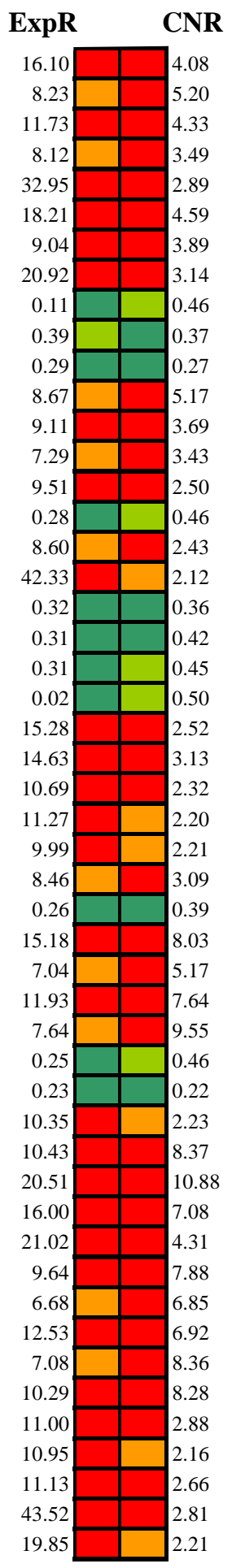

Xenograft

CNR

$\square .47$

5.39

6.43

4.25

3.51

2.84

5.11

4.64

0.52

0.40

0.43

2.91

3.09

3.12

2.48

0.73

2.47

1.56
0.48

0.46

0.62

0.53

1.97

3.18

1.68

1.91
1.67

1.23

0.44

4.42

3.51

5.68

6.34

0.51

0.51

1.97

6.20

6.60

3.36

2.65

5.79

5.14

6.53

5.69

5.40

2.22

2.25

1.84

2.34 